Published in "Clinical Anatomy 30(6): 700-702, 2017"

which should be cited to refer to this work.

\title{
Ordering by the Numbers in Anatomy and by Letters Too
}

\author{
PAUL E. NEUMANN, ${ }^{1} *$ ROBERT BAUD,${ }^{2,3}$ AND PIERRE SPRUMONT ${ }^{\mathbf{2}}$ \\ ${ }^{1}$ Department of Medical Neuroscience, Dalhousie University, Halifax, Nova Scotia, Canada \\ ${ }^{2}$ Anatomy, Department of Medicine, University of Fribourg, Fribourg, Switzerland \\ ${ }^{3}$ SIB Text Mining, Swiss Institute of Bioinformatics, Geneva, Switzerland
}

\begin{abstract}
Here, new rules of Latin anatomical nomenclature are proposed to deal with cases not covered by existing or other recommended rules. Determiners (e.g., numerals, letters, alphanumeric strings, and Latin names of Greek letters) should follow the noun they specify or limit, just as it is recommended that adjectives should follow the noun they modify. In general, Roman numerals, Latin letters, and Latin names of Greek letters are preferable to Arabic numerals and Greek letters in Latin anatomical terms. It is also noted that the word typus (type) appears to be superfluous and unnecessary in the Latin anatomical nomenclature.
\end{abstract}

\section{Key words: anatomical nomenclature; anatomical terminology; Latin anatomi- cal terms}

The IFAA anatomical terminologies (FCAT, 1998; FICAT, 2008; FIPAT, 2013, 2017) use Latin and Greek letters, Roman and Arabic numerals, and alphanumeric combinations (short strings of characters) to indicate specific individual members of a set. These determiners, which specify or limit nouns, function like ordinal numbers, which are determiners as well as adjectives in linguistics. Roman numerals may be considered substitutes for ordinal numbers (see Table 1). Letters, whether they are used as part of an alphabetic sequence or as abbreviations of nouns and adjectives, can be treated as determiners (see Table 2).

Usage of alphanumeric determiners varies quite a bit in anatomical terminology because there are no rules that govern their use in anatomical terms. For example, Greek letters, or their Latin names, have appeared at the beginning or end of terms (e.g., alpha granulum glycogeni, tubulinum beta, motoneuron $\gamma$ ), and numerals are usually found at the end of terms. As part of the effort to simplify and clarify the meaning of Latin anatomical terms, the following guidelines for the use of letters, numerals, and alphanumeric combinations are recommended:

1. Alphanumeric determiners and names of Greek letters should follow the noun they limit or specify.
2. Roman numerals and Latin letters are generally preferred in Latin terms.

In some cases, especially in alphanumeric combinations, there may be traditional use of Latin or Greek letters, and of Roman or Arabic numerals. Arabic numerals are acceptable, especially in alphanumeric strings where Roman numerals may be confused with Latin letters and in cases where the entity is commonly associated in the literature with Arabic rather than Roman numerals (see Table 3). A space between Latin letters and Roman numerals may help distinguish them. Superscripts and subscripts should be avoided because they are not supported by ASCII codes (ASA, 1963).

Terms usually associated with Greek letters $(\alpha, \beta, \gamma$, etc.) should use the Latin names of these Greek letters (alpha, beta, gamma, etc.) (see Table 4).

*Correspondence to: Dr. Paul E. Neumann, Department of Medical Neuroscience, Faculty of Medicine, Dalhousie University, Halifax, Nova Scotia, Canada B3H 4R2. E-mail: paul.neumann@ dal.ca 
TABLE 1. Examples of Terms Containing Roman Numerals

Lamina I isocorticis

Digitus II pedis

Regio III cornus ammonis

Vertebra cervicalis IV

Os $\mathrm{V}$ metacarpi

Costa VI

Segmentum VII hepatis

Bronchus VIII pulmonis sinistri

Lamina spinalis IX

Lobulus $X$ hemisphaerii cerebelli

Nervus cranialis XI

Nervus thoracicus XII

Exclusive use of the Latin alphabet simplifies anatomical terms and makes them more compatible with computer applications because Greek letters are not included in the seven-bit ASCII code table, and only a few Greek letters are represented among the "extended ASCII characters" (eight-bit codes) of ISO/ IEC 8859-1 (ISO/IEC JTC1, 1998). The names of Greek letters are indeclinable neuter nouns, so there are no plural or genitive forms. Although use of the name of the Greek letter with a Latin noun is technically an apposition (Neumann, 2017), the name of the Greek letter is a substitution of convenience for the Greek letter so it can be treated in anatomical terminology simply as a determiner.

The word typus (type) has occasionally been used in IFAA terminologies (e.g., pneumocytus typus $I$, fibra collageni typi III, typus ampullaris pelvis renalis). In fact, use of the word typus can be described as sporadic and irregular. The word is probably superfluous or unnecessary in most, if not all, anatomical terms in which it appears. Pneumocytus $I$,

TABLE 2. Examples of Terms Containing Latin Letters

Anaphasis A

Spermatogonium B

Thyrocytus C

Facies E

Stria $\mathrm{H}$

Crus $\mathrm{p}$

Endocrinocytus PYY

Lymphocytus T

Chromosoma X

Linea Z

TABLE 3. Examples of Terms Containing Alphanumeric Combinations

Neuron retinale $A 8$

Vertebra C4

Regio CA3

Neuromerus D2

Phasis G1

Nervus spinalis T12

Lamina 6b isocorticis

Endocrinocytus delta 1

Lobulus H X cerebelli
TABLE 4. Examples of Terms Containing Names of Greek Letters

Pars alpha nuclei gigantocellularis

Actininum alpha

Internexinum alpha

Filamentum internexini alpha

Tubulinum beta

Endocrinocytus beta

Motoneuron gamma

Granulum gamma glycogeni

Granulum delta thromobocyti

Locus lambda

TABLE 5. Examples of Terms that Could Be Simplified By Removing the Word typus

\begin{tabular}{ll} 
Current term & \multicolumn{1}{c}{ Recommended term } \\
\hline Cellula Tadjuvans typi II & Cellula Tadjuvans II \\
Epitheliocytus intercalatus & Epitheliocytus intercalatus A \\
typus A & \\
$\begin{array}{c}\text { Epitheliocytus reticularis } \\
\text { typorum I-III }\end{array}$ & Epitheliocyti reticulares I-III \\
$\begin{array}{l}\text { Fibra collageni typi III } \\
\text { Pneumocytus typus I }\end{array}$ & Fibra collageni III \\
$\begin{array}{l}\text { Typus ampullaris pelvis } \\
\text { renalis }\end{array}$ & Pneumocytus I \\
& Pelvis renalis ampullaris \\
\end{tabular}

fibra collageni III, and pelvis renalis ampullaris are shorter, simpler, and sufficient (see Table 5). Although punctuation and other special characters should be avoided in anatomical terms, dashes are useful in plural terms in which a range of values is specified (e.g., epitheliocyti reticulares I-III, laminae spinales III-IV).

As with the established and proposed rules for Latin anatomical nomenclatures (Neumann et al., 2017), the guidelines suggested here are intended for Latin terms not for equivalents in other languages. For example, in many modern languages, Arabic numbers will be preferable to Roman numerals in anatomical terms.

Errata: In response to earlier publications in this series (Neumann, 2017; Neumann et al., 2017), W. A. C. van de Riet (The Netherlands) noted that os ischium does not actually appear in Terminologia Anatomica (FCAT, 1998), and that musculus psoas major is not necessarily an apposition. Although psoas is usually interpreted by anatomists to be a nominative singular masculine noun (Faller, 1978), or a transliteration of a variant (archaic or Ionic) Greek nominative plural feminine noun (Liddell et al., 1996), it can also be considered a transliteration of a Greek genitive singular feminine noun (Hyrtl, 1880). Thus, musculus major psoae is an alternative to the Regular Anatomy (RA) term psoas major.

\section{ACKNOWLEDGMENTS}

The authors thank Drs. John Fraher and Wim van de Riet for reviewing the manuscript. 


\section{REFERENCES}

ASA (American Standards Association). 1963. American Standard Code for Information Interchange. New York: American Standards Association.

Faller A. 1978. Die Fachwörter der Anatomie, Histologie und Embryologie. 29th Ed. Munich: J. F. Bergmann.

FCAT (Federative Committee on Anatomical Terminology). 1998. Terminologia Anatomica. Stuttgart: Thieme.

FICAT (Federative International Committee on Anatomical Terminology). 2008. Terminologia Histologica. Philadelphia: Lippincott Williams \& Wilkins.

FIPAT (Federative International Programme on Anatomical Terminology). 2013. Terminologia Embryologica. Stuttgart: Thieme.
FIPAT. 2017. Terminologia Neuroanatomica. URL: FIPAT.library.dal.ca/TNA. [accessed on February 2017].

Hyrtl J. 1880. Onomatologia Anatomica. Vienna: Wilhelm Braumüller. ISO/IEC JTC1 (Joint Technical Committee 1). 1998. ISO/IEC 8859-1, Information technology - 8-bit single-byte coded graphic character sets - Part 1: Latin alphabet No. 1. Geneva: International Standards Organization and International Electrotechnical Commission.

Liddell HG, Scott R, Stuart Jones H, McKenzie R. 1996. GreekEnglish Lexicon. 9th Ed. with supplement. Oxford: Oxford University Press.

Neumann PE. 2017. Elimination of the apposition in Latin anatomical terms. Clin Anat 30:156-158.

Neumann PE, Baud R, Sprumont P. 2017. Human anatomy nomenclature rules for the computer age. Clin Anat 30:300-302. 